\title{
ABOUT THE NEED FOR DEVELOPING RISK MANAGEMENT FOR ENSURING SAFETY FROM ANTIOBIOTIC AND VETERINARY DRUG RESIDUES IN KAZAKHSTAN
}

\author{
AITUGAN SABITOV*1, NAILYA IBRAGIMOVA ${ }^{1}$, MARINA LYU ${ }^{1}$ AND DIDAR BOLATOVA ${ }^{1,2}$

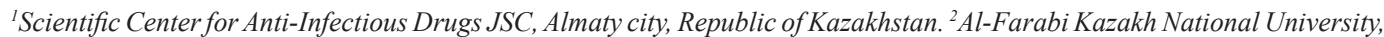 \\ UNESCO Chair for Sustainable Development, Almaty city, Republic of Kazakhstan.
}

*Corresponding author: sabitov.an@scaid.kz

Submitted final draft: 18 August $2020 \quad$ Accepted: 27 August 2020

http://doi.org/10.46754/jssm.2021.06.022

\begin{abstract}
In connection with the integration of Kazakhstan into the international agricultural consortium, the scientific principles of risk management for veterinary drugs in environmental objects and livestock products and the need for monitoring and control to ensure safety of agricultural products is required. This research paper aims to conduct an assessment of the potential risk of harm to the health of consumers through an analysis of the probability of violation of the legislative requirements for food safety. It also briefly describes the regulations on administration of veterinary drugs in Kazakhstan. And found concentrations of ciprofloxacin, metronidozole and diclofenac in the water from Sorbulak Lake. This paper also proposes measures that should be applied in the future to ensure product and environment safety with regards to drug residues in Kazakhstan. And looks at the creation of a modern system of management and recycling of drug residues for transition of the Republic of Kazakhstan to a "green" economy with sustainable development.
\end{abstract}

Keywords: Risks management, pharmaceutical and veterinary drugs residues, agricultural products, livestock farming, wastewater.

\section{Introduction}

In recent years, the risks of accumulation of the biotransformation residuals of veterinary and pharmaceutical drugs in products and raw materials of animal and vegetable origin began to grow due to an increase in the number of drugs used in agriculture. A rapidly growing population leads to a progressive demand for more products of animal and vegetable origin, which is accompanied by agricultural intensification and an increase in the use of antimicrobial agents, chemicals, feed additives, etc.

Global consumption of antimicrobials is projected to rise by $67 \%$ by 2030 (Van Boeckel et al., 2015). Only between 2000 and 2010, the consumption of antibiotics in humans has increased by $36 \%$. 3.3 million $\mathrm{kg}$ of antibiotics for human use and 13.6 million $\mathrm{kg}$ for animal use were sold in 2011, that is, $80 \%$ of world production was intended for agriculture (Van Boeckel et al., 2014).

Antibiotics, antiparasitic agents and steroid hormones are currently the most widely used. Higher than normal concentrations of veterinary drugs (antibiotics) and their residue in agricultural products causes direct and indirect risks from a public health point of view. Direct risks are short-term, indirect risks are longer-term. Some antibiotics can cause toxic reactions in consumers directly. For example, it is known that between $4 \%$ and $11 \%$ of the human population is allergic to penicillin and related drugs (Dayan, 1993). Indirect hazards are manifested in the form of microbiological effects, carcinogenic effects, reproductive effects and teratogenicity. Microbiological effects are one of the main dangers to human health. Antibiotic residues consumed with food products such as milk, meat and eggs can cause resistance in bacterial populations. Some drugs, such as nitroimidazoles, increase the risk of cancer (Lv \& Zhu, 2015).

Antibiotics are also administered in subtherapeutic doses as feed additives to stimulate growth, increase weight of animals and as a prophylactic agent against infectious diseases (see Sarmah et al., 2006; Chowdhury et al., 2014). It should be considered that 
the composition of drugs along with active substances also includes inactive components, which, while undergoing metabolic processes in the body, can transform into an active form and serve as a source of environmental pollution (Arnold et al., 2013).

Intensive livestock farming and aquaculture is the main entry point of drug residues and their metabolites into soil and water sources. While there these, pharmacological preparations and chemicals impact living organisms, causing various types of effects that can be divided into three groups as follows:

a) Group 1 - the toxic effects at any level of the biological hierarchy: cells - organs organisms - population - ecosystem

b) Group 2 - the effects of antibiotics on pathogens and the development of their resistances

c) Group 3 - the effect on endocrine organs, in which the normal hormonal profile of living organisms is disturbed (Jorgensen \& Halling-Sorensen, 2000).

It has been seen that between $30 \%$ and $90 \%$ of veterinary drugs are excreted with feces and urine, followed by the in vivo biotransformation (Franklin et al., 2016). Researchers have detected toxic effects of veterinary antimicrobials, antiparasitic agents, chemotherapeutic drugs, antibiotics and feed additives that get into the environment and affect many species of living organisms (Jjemba, 2002; Tisler \& Erzen, 2006; Wagil et al., 2015).

Since 1998, the use of antibiotics to stimulate growth has been prohibited in European Union. In 2017, 56 of 134 member countries in the World Organization for Animal Health actively studied data on the use of antibiotics in agriculture (World Health Organization, 2016; Food and Agriculture Organization, 2017).

Several authors have found that in each agricultural watershed - area of land that drains or "sheds" water into a specific waterbody - under study has a combination of several sources of pharmacological preparations that have leached into the soil and water, meanwhile veterinary and mixed pharmaceutical drugs continue to be used. Fish are not able to metabolise antibiotics, which are largely returned to the environment. Some antibiotics are poorly absorbed in the intestines of animals; most of them are therefore excreted with feces in transformed, conjugated polar molecules, or even excreted in a largely unchanged form (Jaime et al., 2012; Jaffrézic et al., 2017).

Antibiotics used vary from country to country. There is evidence of a logical relationship between antimicrobial resistance in both humans and livestock and the formation of antibiotic resistant genes can accumulate, reducing the effectiveness of available treatments leading to the use of larger doses or stronger drug options. The application of manure contaminated with antibiotics contributes to the formation of antibiotic resistant genes in soil flora and fauna. Bacterial strains found in soil and manure are phylogenetically close to the causative agents of human infections, which makes genetic exchange in the soil more likely (Heuer et al., 2011; Hille et al., 2017). Currently, there is evidence of a logical relationship between antimicrobial resistance in both humans and livestock and the formation of antibiotic resistant genes that can accumulate, reducing treatment (see Durso \& Cook, 2014; Zhang et al., 2015).

Kazakhstan, being an agro-industrial country and an active participant in integration unions in the Eurasian space, planning programmes for intensifying livestock production, trying to enter the market for organic products, will inevitably face the problem of the drug residue entry into agricultural products, soil and water, environmental pollution and occurrence of drug resistance in the commensal bacteria.

It is therefore necessary to develop a national strategy related to the systematisation, management and optimisation of the use of veterinary drugs, a food safety control programme, standards for the content of drug residuals in accordance with international standards and a plan to combat the resistance in microorganisms. 
The risk management of pharmaceutical and veterinary drugs will contribute to the implementation of the Law of Republic of Kazakhstan on the "production of organic products", which provides for the rejection of the use of pesticides, synthetic mineral fertilizers, growth regulators, artificial food additives, since the production and sale of organic agricultural products are an objective competitive advantage of the agro-industrial complex in Kazakhstan.

\section{Materials and Methods}

\section{Potential Risk Assessment}

Official statistical information in the form of express information, the dynamics of the main indicators, graphic materials and in other forms is presented on the website of the Committee on Statistics of the National Economy Ministry, Republic of Kazakhstan - http://stat.gov.kz/ faces/.

The frequency (probability) of violations of mandatory safety requirements for food products by the i-th hazard factor during one check $\left(\mathrm{p}_{\mathrm{i}}\right)$ is determined according to the form of industry statistics as the ratio of the number of research results with violation of requirements and norms to the total number of studies:

$$
\mathrm{p}_{\mathrm{i}=} \mathrm{m}_{\mathrm{i}} / \mathrm{n}_{\mathrm{i}}
$$

Where $m_{i}$ is the number of studies on food products more than the normative value of the $i$-th factor per year; $n_{i}$ is the total number of studies of the $i$-th factor per year.

The potential health risk when the population consumes a particular type of product is determined by the formula:

$$
R_{i}=\Sigma\left(p_{i} \cdot u_{i}\right) \cdot W
$$

Where $p_{i}$-theprobabilityofviolationsofmandatory safety requirements for food products by the $\mathrm{i}$-th hazard factor during one inspection; $\mathrm{u}_{\mathrm{i}}-$ relative damage to health caused by violation of sanitary and epidemiological requirements for the i-th food product hazard factor; W - coefficient characteristion the regional particularities in consumption of various food products.

\section{Wastewater Sample Selection}

The Sorbulak Lake storage has more than 40year history of operation and is one of the world's largest lakes-sedimentation tanks for sewage treatment. Wastewater of Almaty city, the largest city of Kazakhstan, that has passed mechanical and biological purification is dumped into the lake. The Sorbulak basin primarily functions as a deep, long-term regulator of the sewage levels and provides natural self-purification of water for subsequent use in irrigation. Five tonnes of water comes into Sorbulak every second and the total volume of the accumulator tank is 900 million cubic meters with an optimum mark and normal retaining level of between 620.5 and 622 metres. To unload the Sorbulak, a channel was therefore put in place in the Ili River (on the right-bank of Sorbulak Lake). The channel drains the water into a reservoir with a capacity of up to 50 million cubic metres.

Wastewater samples that were taken after the biological treatment stage on Sorbulak Lake at the following geographical coordinates: Lower level $76.876184^{\circ}$ East and $43.411108^{\circ}$ North; Upper level $76.731531^{\circ}$ East and $43.458816^{\circ}$ North; $76.530507^{\circ}$.

To test the stage of the transformation of the "living organism-environment", drugs based on the general availability, the list of essential medicines and the category of antiinfective drugs were selected: diclofenac (a group of nonsteroidal anti-inflammatory drugs), cephalosporins (synthetic antibiotics), metranidozole (a group of nitroimidazole and antiprotozoal).

Diclofenac is a derivative of phenylacetic acid, belonging to the class of non-steroidal antiinflammatory drugs (NSAIDs), which have antiinflammatory, antipyretic, analgesic, antiplatelet and uricosuric effects. The drug binds to plasma proteins by almost $99.7 \%$. Diclofenac is metabolised by oxidation and glucoronidation and only about $1 \%$ is excreted unchanged in the urine (Smith et al., 2012). 
Metronidazole belongs to the group of nitroimidazoles, it is effective against anaerobes and in general in the treatment of bacterial infections and infections caused by protozoa, such as amoebiasis Clostridium. Metronidazole is included in the list of essential medicines of World Health Organization (WHO) as a basic medicinal product (Freeman et al., 1997). Cephalosporins have high therapeutic activity and are widely used in medicine and veterinary medicine, but their transformation in environmental objects is not known.

The time of degradation of four cephalosporins (cefradins, cefuroxime, ceftriaxone and cefepime) was studied in the surface waters and only four cephalosporins were amorphously degraded with half-lives of between 2.7 and 18.7 days. (Jiang et al., 2010).

Determination of the selected antibiotics (ciprofloxacin, metronidozole) and diclofenac in liquid samples was carried out using solid-phase extraction with a preliminary concentration step. The cartridges were conditioned by washing them with $6 \mathrm{ml}$ of methanol, $6 \mathrm{ml}$ of $0.5 \mathrm{M} \mathrm{HCl}$ and $6 \mathrm{ml}$ of water. Samples were percolated through cartridges at a flow rate of between $5 \mathrm{ml}$ and $20 \mathrm{~mL} / \mathrm{min}$.

For this purpose, 1litre of each sample was filtered through glass fiber $(0.45 \mu \mathrm{m}$ pore $\varnothing)$. Before filtration, the $\mathrm{pH}$ of each sample was adjusted to between 2.0 and 3.0. Analytes were eluted with $20 \mathrm{ml}$ of methanol, the extract was evaporated to dryness. The dry sample was recovered in $1 \mathrm{ml}$ of methanol, filtered and the extract was then analyzed. Chromatographic separation was performed using a reverse phase analytical column.

The mobile phase consisted of a mixture of acetonitrile and $0.1 \%$ formic acid in water. Gradient elution began at $10 \%$ solution A and increased to $80 \%$ within three minutes, after which it decreased to $10 \%$ within 0.1 minutes and stabilized within 1.9 minutes with a total time of five minutes.

The injection volume was $2 \mu 1$, the flow rate was fixed at $1.0 \mathrm{ml} / \mathrm{min}$. The limit of detection and limit of quantification were calculated and calibration curves were prepared for each compound.

\section{Results and Discussion}

\section{Determination of Potential Risks to Public Health}

At the consumer market such a significant number of goods and agricultural products are in circulation that their total control is absolutely impossible. In such a situation, risk-oriented supervision of products allows the control authorities to select products with the highest health risk for documentary and laboratory studies.

Understanding the relevance of such approaches leads to the emergence of methodological documents that classify products. So, in the Republic of Kazakhstan there are objects of high epidemic importance and objects of insignificant epidemic importance (which respectively can be considered as objects with high or insignificant risk).

Among the products of high epidemic importance, there are, along with others, food products (products in natural or processed form used by humans for food), including those produced which use genetically modified (transgenic) organisms.

We have done a mathematical analysis of the database of the Statistics Committee of the Ministry of National Economy of the Republic of Kazakhstan, which allows us to estimate the likely frequency of violations that have been identified in relation to different types of products. The established frequencies in relation to the measured laboratory parameters are shown in Table 1 (more than 20 thousand measurements). This frequency is determined for all categories of product non-compliance with standards.

An important element of the organization of risk-oriented supervision of product safety is the formation of laboratory research programs (measurements). Our analysis of the results 
of control and supervision activities permits to register and perform an analysis of the frequencies of violations of specific indicators (Table 2).
The authorized body of the Republic of Kazakhstan in the field of application of sanitary measures is the Committee for Quality and Safety Control of Goods and Services of the Ministry of Health of the Republic of

Table 1: The frequency of violations of mandatory requirements for the levels of chemical, biological and physical factors normalized in food products (2017-2019)

\begin{tabular}{lc}
\hline \multicolumn{1}{c}{ Type of Food Products } & $\begin{array}{c}\text { Frequency of Violations Identified } \\
\text { During } \mathbf{1} \text { Inspection }\end{array}$ \\
\hline Milk, dairy products & 0.270 \\
Meat and meat products & 0.265 \\
Oil and fat products & 0.247 \\
Poultry and poultry products & 0.481 \\
Fish, fish products and other aquatic organisms & 0.504 \\
Grain and grain products & 0.151 \\
Flour and cereal products & 0.278 \\
Vegetables & 0.236 \\
\hline
\end{tabular}

Table 2: The probability of violation of the mandatory requirements for product safety, calculated on the basis of the results of control measures

\begin{tabular}{|c|c|c|c|c|c|c|c|c|c|}
\hline Type of food products & 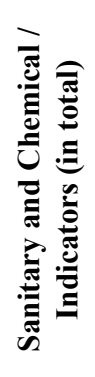 & 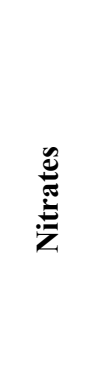 & 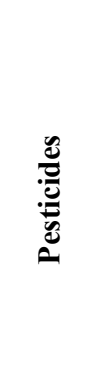 & 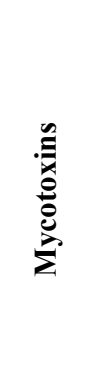 & 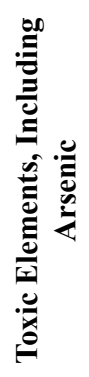 & 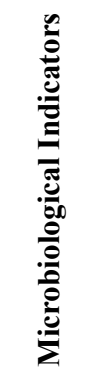 & 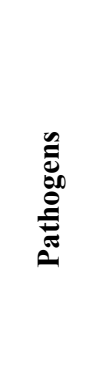 & 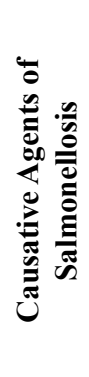 & 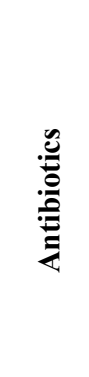 \\
\hline Milk, dairy products & 0.081 & - & 0.000 & 0.000 & 0.000 & 0.139 & 0.004 & 0.000 & 0.046 \\
\hline Meat and meat products & 0.077 & 0.000 & 0.000 & - & 0.000 & 0.127 & 0.018 & 0.011 & 0.032 \\
\hline Oil and fat products & 0.124 & - & 0.000 & 0.000 & 0.005 & 0.108 & 0.000 & 0.000 & 0.010 \\
\hline $\begin{array}{l}\text { Poultry and poultry } \\
\text { products }\end{array}$ & 0.140 & - & 0.000 & - & 0.000 & 0.124 & 0.079 & 0.071 & 0.067 \\
\hline $\begin{array}{l}\text { Fish, fish products and } \\
\text { other aquatic organisms }\end{array}$ & 0.157 & - & 0.000 & - & 0.000 & 0.229 & 0.101 & 0.005 & 0.012 \\
\hline $\begin{array}{l}\text { Grain and grain } \\
\text { products }\end{array}$ & 0.048 & - & 0.000 & 0.000 & 0.000 & 0.103 & - & - & - \\
\hline $\begin{array}{l}\text { Flour and cereal } \\
\text { products }\end{array}$ & 0.093 & - & 0.000 & 0.005 & 0.000 & 0.180 & 0.000 & 0.000 & 0.000 \\
\hline Vegetables & 0.080 & 0.088 & 0.001 & 0.000 & 0.017 & 0.051 & 0.000 & 0.000 & - \\
\hline
\end{tabular}

Note: "_" data are not available or not tested 
Kazakhstan. In the Republic of Kazakhstan, information about products that do not meet mandatory requirements is accumulated in form 18 (annual), approved by Order of the Minister of Health of the Republic of Kazakhstan dated March 6, 2013 No. 128. Form 18 (annual) is intended for the collection of administrative data submitted in accordance with the Code of the Republic of Kazakhstan on the "health of the people and the healthcare system".

Information on food consumption by the population of the Republic of Kazakhstan is contained in the statistical collection "Living Standards of the Population in Kazakhstan", which is published annually by the Statistics Committee of the National Economy Ministry of the Republic of Kazakhstan at web www. stat.gov.kz. The collection includes tabular materials characterising the socio-economic situation of the population in the Republic of Kazakhstan. Statistical materials on the incomes of the population and the unevenness of their distribution, social security and social assistance to the population are presented. Materials from current statistical reporting and sample surveys of the population were used in the present article.

The severity of health responses was determined based on data from the WHO as the ratio of mortality to morbidity due to a given disease (group or class of diseases) (World Health Organization, 2016).

The potential risk of harm to health was calculated for each type of food, for which the research group had relevant statistical information. The calculated value was correlated with the range of values for the potential risk of harm to health, corresponding to the scale for the classification of hazardous products (Table $3)$.

As can be assumed from the analysed data on potential risk, food products according to the possible level of antibiotic content belong to high-risk and significant-risk classes. Products of this class are subject to documentary and laboratory control in $100 \%$ of planned inspections for agricultural producers.

To verify compliance with the requirements established by the legislation of the Republic of Kazakhstan in the field of sanitary and epidemiological surveillance, the frequency of inspections at facilities of high epidemic importance should not be more often:

- once every six months — with a high degree of risk;

- once a year - with an average degree of risk.

The frequency of inspections in the field of sanitary and epidemiological welfare is determined by criteria for assessing the degree of risk. The criteria for assessing the degree of risk are a combination of quantitative and qualitative indicators that we have identified above.

Based on the principles of risk assessment as a combination of the probability of violation of mandatory sanitary requirements for products, as well as the likelihood and severity of the consequences of these violations, a model for organizing risk-based supervision is needed in the future:

Table 3: The ratio of the potential harm to health $\left(\mathrm{u}_{\mathrm{i}}\right)$ in the use of food in violation of sanitary and hygienic requirements for the content of antibiotics

\begin{tabular}{ccccc}
\hline Products & $\boldsymbol{u}_{\boldsymbol{i}}$ & $\boldsymbol{W}$ & $\boldsymbol{R}_{\boldsymbol{i}}$ & Hazard class \\
\hline Milk, dairy products & $4,10 \mathrm{E}-04$ & $1,54 \mathrm{E}+02$ & $2,9 \mathrm{E}-03$ & 3 \\
Meat and meat products & $1,90 \mathrm{E}-04$ & $4,44 \mathrm{E}+02$ & $2,7 \mathrm{E}-03$ & 3 \\
Poultry and poultry products & $3,50 \mathrm{E}-04$ & $1,24 \mathrm{E}+02$ & $2,9 \mathrm{E}-03$ & 3 \\
$\begin{array}{c}\text { Fish, fish products and other } \\
\text { aquatic organisms }\end{array}$ & $6,20 \mathrm{E}-03$ & $1,75 \mathrm{E}+02$ & $1,3 \mathrm{E}-02$ & 2 \\
\hline
\end{tabular}

Note: potential hazard class: 1- extremely high; 2 - high; 3 - significant; 4 - medium; 5 - moderate; 6 - low. 
1) Classification of the potential risk of harm to the activities of producers involved in the circulation of agricultural products.

Methodological support will make it possible to identify those legal entities and/ or individual entrepreneurs whose activities in the field of production, trade, public catering do not meet the requirements of sanitary legislation to the greatest extent and pose risks to the health of consumers, as well as establish the frequency of scheduled risk-based inspections; adequate to risks.

2) Classification of products according to consumer health risks

Methodological support based on the actual frequency of violation of mandatory sanitary requirements for products and the consequences of these violations will highlight those types of consumer products that are the "riskiest" for consumers.

3) Formation of a risk-oriented differentiated laboratory support of planned control and supervision activities.

\section{Regulation on Administration of Veterinary Drugs in Kazakhstan}

The fundamental document in the field of veterinary science of Kazakhstan is the Law of the Republic of Kazakhstan "On veterinary medicine" (as amended and supplemented on 30.05.2020) (Law No. 339-II, 2002). General safety requirements for veterinary drugs, feed and feed additives for animals that are not intended for use as food for humans are described in Chapter 3-1 of this document. Section 24-4 of the Law describes the safety requirements for the use of veterinary preparations, feed and feed additives. The residues and components of veterinary preparations are mentioned only in a single sentence:

"The residues of substances or components of veterinary preparations in products derived from animals in respect of which they were used should not exceed the standards established by the legislation of the Republic of Kazakhstan".
Safety monitoring of veterinary drugs, feed and feed additives is carried out in the manner prescribed by Order of the Minister of Agriculture of the Republic of Kazakhstan dated April 6, 2012 No. 18-02/158 on approval of the Rules for monitoring the safety of veterinary drugs, feed and feed additives (as amended on 11.06.2014).

Currently, by type of product, the Technical Regulation of the Customs Union on the "Safety of Meat and Meat Products" is in force in Kazakhstan. This document determines the maximum permissible levels of residues of veterinary (zootechnical) drugs, animal growth stimulants (including hormonal drugs) and drugs (including antibiotics) in slaughter products, controlled according to information on their use. Control (except for chloramphenicol, tetracycline group and bacitracin) is carried out based on information on their use provided by the manufacturer (supplier) of slaughter products when they are imported into the customs territory of the Customs Union (TRCU, 2013).

In addition to these regulations, there are persuasive non-mandatory for use Decision of the Board of the Eurasian Economic Commission dated February 13, 2018 No. 28 "About the maximum permitted levels of veterinary drug residues (pharmaceutically active substances), which may be contained in unprocessed food products of animal origin, including raw materials and methods for their determination" (Decision of the EEC Board No. 28, 2018).

The document raises several significant risks that may create obstacles for participants in the market for the production and processing of animal products and significantly destabilise the food market. The expansion of the list of antibiotics, the contents of which market participants will have to monitor, therefore entailed a significant increase in the costs of manufacturers and processors for this control.

The decision also did not define the frequency of monitoring the maximum allowable levels. Moreover, there are no methods of rapid 
analysis for a significant part of the veterinary drugs which previously were not in the list of tested and thus the technical ability to identify these antibiotics. The proposed research methods (for example, associated with the growth of microbial cultures on test samples) often require a significant investment of time, so valuable for perishable raw materials of animal origin (for example, the shelf life of raw milk is only 36 hours).

A brief review of the regulatory documentation on the one hand and the results of assessing the potential risk of food products on the other hand allow us to conclude about necessity of preparing a methodological document that will regulate the classification of objects subject to state sanitary and epidemiological surveillance as a specific risk group according to the criteria of acceptable risk of harm to human health, which aims to:

- determine the level of unacceptable risk to human health caused by antibiotics;

- justify the risk scale, in accordance with which the inspected objects can be assigned to one or another risk group;

- establish criteria for the admissible risk of harm to human health, including taking into account the likelihood of harm occurrence, severity of probable violations of human health, the population under the influence of an epidemiologically significant object; disorders

- $\quad$ regulate the numerical values of the criteria for assessing the risk of an object subject to sanitary and epidemiological surveillance.

Despite some difficulties and public discussions at present, there are 32 standard methods used to determine drug residues in Kazakhstan. The Kazakhstan Agriculture Ministry (MoA) also reviewed and filed information on rapid residue testing kits, introduced provisions on the withdrawal periods for 78 veterinary drugs and feed additives and promulgated rules on the use of medicinal feed additives.
The National Reference Center for Veterinary Medicine was established in 2013 for the testing of veterinary drug residues and more than 20 provincial veterinary drug residue detection laboratories. The laboratory transformations and updating of equipment and facilities were started in 2013.

In 2013, the Scientific Center for AntiInfectious Drugs (SCAID) passed the inspection and accreditation for GLP compliance carried out by inspectors from the GLP Federal Bureau (Federal Republic of Germany) according to international GLP standards. On March 31, 2014, the GLP Federal Bureau issued a certificate of compliance to show that SCAID can carry out safety studies in accordance with the Organization for Economic Cooperation and Development Principles of GLP (GLP-Test Facilities, 2020).

The GLP rules are formally defined as a quality system regarding the organisational process and the conditions under which safety studies in the sphere of effects of chemicals (pharmaceutical and veterinary drugs, pesticides, food and feed additives, industrial and household chemicals and dyes, etc.) on health and environment should be conducted. Principles could apply to the work of pharmacological, toxicological and other laboratories and are aimed at ensuring the acceptability of safety research results also in veterinary pharmacy.

In 2014 one of a fundamental university of Kazakhstan - Kazakh National University AlFarabi, launched an initiative to open a special center - United Nations Educational, Scientific and Cultural Organization (UNESCO) Chair for Sustainable Development. This initiative was supported by the Kazakhstan National Commission for UNESCO and Islamic World Educational, Scientific and Cultural Organization (ISESCO) and entered the plan of its activities. Following which, the Energy and Ecology Department was renamed to the UNESCO Chair for Sustainable Development in July 2015. 
The basic activity of this department is to mobilize education, research and public activities of the university partners for a favorable solution of problems in the field of sustainable development and the environment in the Central Asian region. The Chair is actively working on the preparation of competitive specialists in Ecology, Life safety and environmental protection, Geo-ecology and environmental management who own the modern methods of research, modeling and forecasting of ecological processes and can solve complex environmental problems. Pharmaceutical and veterinary drugs residues are the object of next Subjects and lectures:

- Ecological risk and modern bioecology;

- Environmental impact on population;

- Labs on ecological monitoring;

- Agricultural ecology.

\section{The Problem of Antibiotic Content in The Wastewater of Almaty City}

Currently only some indicators of water pollution are normalized. These are acid residues, heavy metals, fuel combustion products, aromatic hydrocarbons, radionuclides, pesticides. Toxicological effects of these substances on living objects, including humans have been studied accordingly. However, the residual products of pharmacological preparations are not included in the list of compulsory water quality measures. Identification of the sources of entry of veterinary pharmacological preparations and chemicals into open water sources is difficult because most of the drugs used in veterinary medicine are also administered in the treatment of humans. In addition, the degree of municipal wastewater treatment is not currently controlled by determining the residual content of drugs. As is known, wastewater, having passed through the stages of treatment, is used for irrigation of agricultural land (Fairbairn et al., 2015).

Within the framework of grant financing of the project AP05132269 "Assessing the potential risk of drug transformation to the formation of microorganism resistance in the environmental objects of urbanised territories" this research team investigated Sorbulak Lake storage (Figure 1).

In previous studies, we found that the physicochemical parameters of water from Lake Sorbulak do not exceed the established Marginal Propensity to Consume (MPC) levels (which is a regulatory requirement), with the exception of the concentration of lead, phenols, polyphosphates. In water extracts from sludge sites, normalized values are exceeded for almost

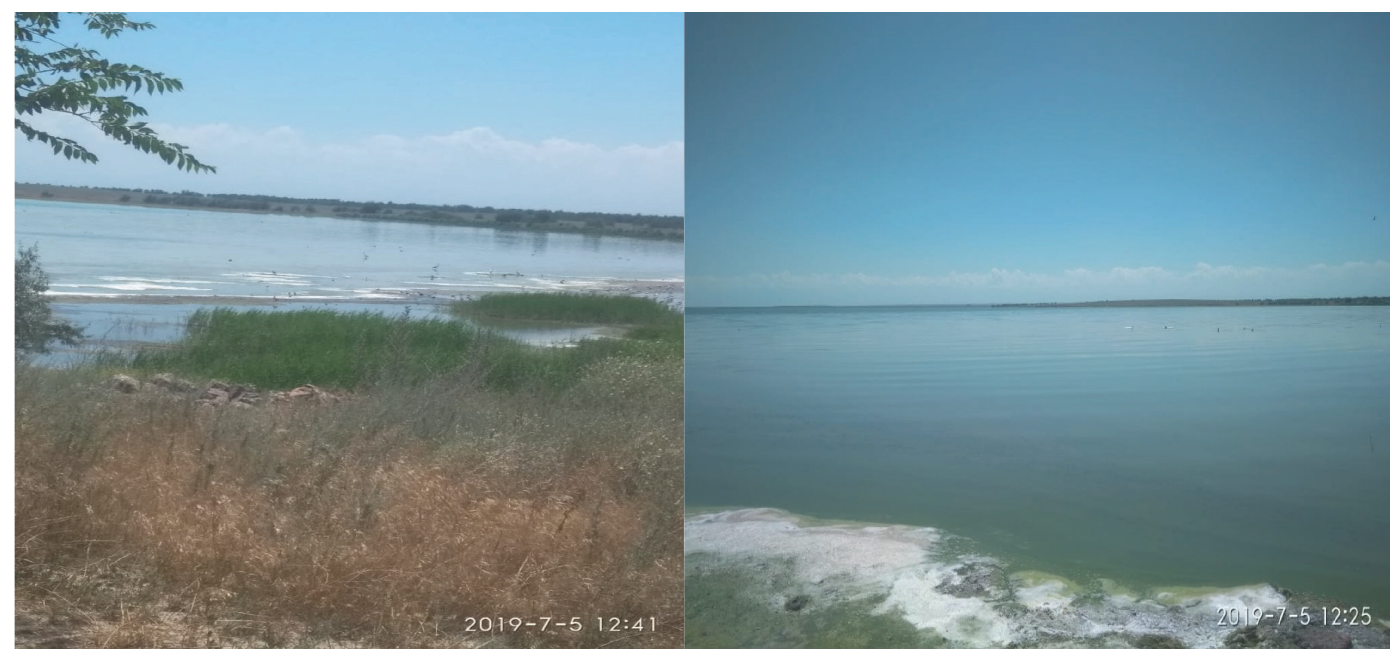

Figure 1: Sorbulak Lake Storage (Ili district, Almaty region, Kazakhstan): Upper Level (left) and Lower level (right) 
all indicators, the level of which increases with increasing shelf life of sludge (Ibragimova et al., 2019a; 2019b).

The results of determining the concentration of drugs in water samples are presented in Table 4. We have found certain levels of drugs in the water of Sorbulak Lake: ciprofloxacin $(0.079 \mu \mathrm{g} / \mathrm{L})$, metronidazole $(0.077 \mu \mathrm{g} / \mathrm{L})$ and diclofenac $(0.05 \mu \mathrm{g} / \mathrm{L})$.

The next step in the research was to determine other pharmaceutical and veterinary drugs residues in water and in aquatic organisms and research mechanisms and to find pathways for wastewater purification of the Sorbulak Lake. To determine the ecotoxicological effect of biotransformed substances in medicinal preparations on sexually mature fish Cyprinus carpio, Abramis brama, Aspius aspius, Silurus glanis, Sander lucioperca, Hypophthalmichthys molitri are caught from Lake Sorbulak and the Ili River. The results of these studies will also be published.

The biggest problem with the collection of data and completion of the study was the lack of metering devices at the wastewater receivers and their discharge is determined mainly by way of calculations. Moreover, the existing water metering devices at the discharge, due to their insufficient technical level, show the amount of effluent that does not correspond to the actual one. For almost all wastewater receivers, departmental and state laboratory control over the quality of discharged water is carried out, however, there are receivers at which there is no laboratory controls and virtually no quality control of discharged effluents is carried out.
A significant number of medicinal substances are poorly biodegradable in the system of treatment facilities and in unchanged form or in the form of metabolites enter the surface water and groundwater. Rationing of environmental risks allows to develop a methodology of reduction of pharmacological preparations residuals in environmental objects and integrate it into the Almaty city development programme, where one of the seven directions is ecology.

\section{Conclusion}

\section{Measures that should be applied in future for ensuring safety from drugs residues in Kazakhstan}

Perfection of the mechanism control the environment through the formation of a new model of management by environmentally oriented methods provides solution of socioecological and economic problems. Next measures should be therefore systematically realised for ensuring safety from pharmaceutical and veterinary drugs residues in Kazakhstan:

a) First, it is necessary to improve the current veterinary drug residues database, more basic information, such as physical and chemical properties of the approved veterinary drugs, data on their pharmacodynamics, pharmacokinetics, adverse drug reaction, medical indications, toxicity to consumers' health and animalderived food consumption data, should be provided. In addition, sub-databases can be established based on the experience of developed countries.

Table 4: The results of determining antibiotic levels in the Sorbulak Lake water

\begin{tabular}{cccc}
\hline Sampling point & \multicolumn{3}{c}{ Drug concentration } \\
\cline { 2 - 4 } & Ciprofloxacin, $\boldsymbol{\mu g} / \mathbf{L}$ & Metronidazole, $\boldsymbol{\mu g} / \mathbf{L}$ & Diclofenac, $\boldsymbol{\mu g} / \mathbf{L}$ \\
\hline $\begin{array}{c}\text { Sorbulak Lake (1) - } \\
\text { lower level }\end{array}$ & 0.048 & 0.050 & 0.014 \\
$\begin{array}{c}\text { Sorbulak Lake (2) - } \\
\text { upper level }\end{array}$ & 0.079 & 0.077 & 0.050 \\
\hline
\end{tabular}


b) In order to control veterinary drug residues from farm to fork, animal-derived food should be produced according to good agricultural practices (GAP), good veterinary practices (GVP), good manufacturing practices (GMP), good laboratory practices (GLP) and good hygiene practices (GHP).

There needs to be a systematic approach for identification and control of hazards associated with food production needs to be implemented to ensure food safety.

c) In order to prevent non-conforming products from appearing on the market without worrying about food safety and protecting consumers' health, it is necessary to take measures to gradually popularize the system of safe access to the markets of Kazakhstan by controlling the process of food production and checking the final products. In addition, in order to track non-conforming samples, it is necessary to improve the tracking and traceability system so that traceability of products of animal origin can be tracked.

d) On the basis of the current veterinary drug residue monitoring programme, it is necessary to further increase the number, coverage and frequency of sampling in the future. To prevent illegal activities such as illegal use of banned chemicals in food-producing animals, it is essential to strengthen inspection of products and increase the severity of punishment.

e) To provide a scientific basis for veterinary drug residue analysis, fundamental research that is related to the mechanism by which residues are generated, in vivo metabolism and elimination and harm to target animals and consumers is needed. Screening methods that are cheaper, easier to use and handle, suitable for multi-residue analysis and field screening and have greater sensitivity, higher throughput and wider detection range are required.

f) It is necessary to conduct a comprehensive study of the impact of the composition and volume of wastewater on ecosystems to ensure environmental safety at the modern level, to make reliable forecasts and recommendations for the effective use of treatment facilities.

g) It is necessary to improve farmers' legal education and convince them that safe food production is their obligation. We should also offer trainings to improve their knowledge on rational use of veterinary drugs.

\section{Acknowledgements}

This research has been funded by the Republic of Kazakhstan Education and Science Ministry under grant number AP05132269.

\section{References}

Arnold, K. E., Boxall, A. B., Brown, A. R., Cuthbert, R. J. et al. (2013). Assessing the exposure risk and impacts of pharmaceuticals in the environment on individuals and ecosystems. Biol. Lett., 9(4), 484-492.

Chowdhury, P. R., \& McKinnon, J. (2014). Genomic interplay in bacterial communities: Implications for growth promoting practices in animal husbandry. Front. Microbiol., 5, 394-395.

Dayan, A. D. (1993). Allergy to antimicrobial residues in food: Assessment of the risk to man. Veterinary Microbiology, 35(3), 213226.

Decision of the EAC No. 28. (2018). https:// docs.eaeunion.org/docs/ru-ru/01017011/ clcd 1502201828

Durso, L. M., \& Cook, K. L. (2014). Impacts of antibiotic use in agriculture: What are the benefits and risks? Curr. Opin. Microbiol., 19, 37-44.

Fairbairn, D. J., Karpuzcu, M. E., et al. (2015). Sediment-water distribution of contaminants of emerging concern in a 
mixed-use watershed. Sci. Total Environ., 505, 896-904.

Food and Agriculture Organization of the United Nations. (2017). The FAO action plan on antimicrobial resistance 2016-2020. http:// www.fao.org/ 3/ a-i5996e.pdf.

Franklin, A. M., Aga, D. S., et al. (2016). Antibiotics in agro systems: Introduction to the special section. J. Environ. Qual., 45, 377-393.

Freeman, C. D., Klutman, N. E., \& Lamp, K. C. (1997). Metronidazole. A therapeutic review and update. Drugs, 54(5), 679-708.

GLP -Test Facilities. (2020). GLP - Test Facilities / Test Sites in the Monitoring Programme, Germany. https://www.bfr.bund.de/cm/349/ good-laboratory-practice-GLP-testfacilities-in-the-monitoring-programmegermany.pdf.

Heuer, H., Schmitt, H., \& Smalla, K. (2011). Antibiotic resistance gene spread due to manure application on agricultural fields. Curr. Opin. Microbiol., 14, 236-243.

Hille, K., Ruddat, I., et al. (2017). Cefotaximeresistant E.coli in dairy and beef cattle farms - joint analyses of two cross-sectional investigations in Germany. Preventive Veterinary Medicine, 142, 39-45.

Ibragimova, N. A., Snow D., Lyu, M. B., \& Sabitov, A. N. (2019a). On the question of the necessity of normating bio-transformed substances medicinal preparations in objects of the environment. Reports of the National Academy of Sciences of the Republic of Kazakhstan, 1(323), 5-10. https://doi.org/10.32014/2019.2518-1483.1

Ibragimova, N. A., Lyu, M. B., Sabitov, A. N., Jumabayeva, S., \& Karzhaubayeva, R. (2019b). The study of biotransformation products and microbiological activity of antibacterial drugs in vivo. 2nd Euro-Mediterranean Conference for Environmental Integration, Sousse, Tunisia, 10-13.
Jaffrézic, A., Jarde, E., Soulier, A., et al. (2017). Veterinary pharmaceutical contamination in mixed land use watersheds: from agricultural headwater to water monitoring watershed. Science of the Total Environment, 609, 9921000.

Jaime, R., Carmen, G. F., \& Paola, N. (2012). Antibiotics in aquaculture use, abuse and alternatives, in health and environment in aquaculture. http://www.intechopen. com/books/health-and-environment-inaquaculture/antibiotics-in-aquaculture-useabuse-and-alternatives

Jiang, M., Wang, L., \& Ji, R. (2010). Biotic and abiotic degradation of four cephalosporin antibiotics in a lake surface water and sediment. Chemosphere, 80(11), 13991405.

Jjemba, P. K. (2002). The potential impact of veterinary and human therapeutic agents in manure and biosolids on plants grown on arable land: A review. Agric. Ecosyst. Environ., 93(3), 267-278.

Jorgensen, S. E., \& Halling-Sorensen, B. (2000). Drugs in the environment. Chemosphere, 40(7), 691-699.

Law No. 339-II. (2002). Law of the Republic of Kazakhstan dated July 10, 2002 No. 339II. On Vetrinary. https://online.zakon.kz/ document/?doc_id=1032052

Lv, P. C., \& Zhu, H. L. (2015). Nitroimidazole derivatives: A patent review of US 2014/0141084 A1. Expert Opinion on Therapeutic Patents, 25(4), 489-492.

Sarmah, A. K., Meyer, M. T., \& Boxall, A. B. (2006). A global perspective on the use, sales, exposure pathways, occurrence, fate and effects of veterinary antibiotics (VAs) in the environment. Chemosphere, 65(5), 725-759.

Smith, F. G., Wade, A. W., Lewis, M. L., \& Qi, W. (2012). Cyclooxygenase (COX) inhibitors and the newborn kidney. Pharmaceuticals (Basel), 5, 1160-1176. 
TRCU. (2013). Technical Regulation of the Customs Union 034/2013.”On the Safety of Meat and Meat Products". https:// docs.eaeunion.org/docs/ru-ru/0043629/ cncd_11102013_68

Tisler, T., \& Erzen, N. K. (2006). Abamectin in the aquatic environment. Ecotoxicology, 15(6), 495-502.

Van Boeckel, T. P., Brower, C., Gilbert, M., Grenfell, B. T., et al. (2015). Global trends in antimicrobial use in food animals. Proc. Natl. Acad. Sci. USA, 112, 5649-5654.

Van Boeckel, T. P., Gandra, S., Ashok, A., Caudron, Q., et al. (2014). Global antibiotic consumption 2000 to 2010: An analysis of national pharmaceutical sales data. Lancet Infect. Dis., 14, 742-750.
Wagil, M., Bialk-Bielinska, A., \& Puckowski, A. (2015). Toxicity of anthelmintic drugs (fenbendazole and flubendazole) to aquatic organisms. Environ. Sci. Pollut. Res., 22(4), 2566-2573.

World Health Organization. (2016). Critically important antimicrobials for human medicine, 5th revision. Geneva. http:// apps.who.int/iris/ bitstream/2017.

Zhang, Q. Q., Ying, G. G., Pan, C. G., Liu, Y. S., et al. (2015). Comprehensive evaluation of antibiotics emission and fate in the river basins of china: Source analysis, multimedia modeling, and linkage to bacterial resistance. Environ. Sci. Technol., 49, 6772-6782. 